\title{
Preface from the Editor-in-chief
}

\author{
Xue-dong Zhou \\ Editor-in-Chief \\ International Journal of Oral Science
}

In 1946, The Dental Journal of West China Union University was launched by Dr. Ashley Lindsay. Dr. Lindsay was the founder of the Dental School in West China Union University, which was also the first dental school in China, and the journal was the first dental and oral journal in the country. Although the journal was finally suspended after 8-years of publication of high-quality academic papers in both Chinese and English, the first dental hospital and dental school, now West China College of Stomatology of Sichuan University, which Dr. Lindsay and his colleagues devoted their lives to, has been providing services to the Chinese people and taught thousands of practitioners and scholars over the past century. Just celebrating its $100^{\text {th }}$ anniversary in 2007 , the college takes pride in being the leading educational and clinical base for dental, oral and maxillofacial sciences in China.

Since Dr. Lindsay's time, giant leaps have been made in the development of dental, oral and maxillofacial sciences and practice in China and around the globe. Nowadays, Chinese dentists and researchers are playing an increasingly active role in international academic exchanges. The whole community of Chinese oral and dental practitioners and scientists are willing to share their wisdom and achievements with their peers around the world.

Today it is my privilege to introduce to you The International Journal of Oral Science (IJOS), a new forum for the foremost discoveries resulting from basic investigations and clinical research relating to oral science. As the first English periodical in this field, with both ISSN and CN certificates on China's mainland, IJOS seeks to publish original, high quality, peer-reviewed papers including research articles and reviews as well as short communications and case reports. IJOS will provide comprehensive coverage on all aspects and subspecialties of oral science. Submissions related to studies in dental assistance and hygiene, education and training, practice management and marketing will also be encouraged in IJOS. IJOS aims to become a highly respected and trusted resource of leading knowledge in this field,promoting worldwide academic exchanges, especially in Asia and the Pan Pacific Area.

Preparation of a new publication takes time and effort; and the first issue of IJOS embodies industrious work on our part and generous support from many distinguished people and organizations. My sincerest appreciation is extended to the co-editors-in-chief, Dr. Page Caufield and Dr. Cun-Yu Wang, and to all members of the editorial board. I would also like to extend my cordial gratitude to the State Key Laboratory of Oral Diseases and the International College of Dentists. We owe many thanks to all the staff members there for their contribution.

As shared by other major international periodicals, Dr. Lindsay's belief is supported by IJOS, namely that an academic journal should be open to all oral and dental professionals in the world, in which new thoughts will be rapidly reported, the interdisciplinary connection be promoted and the purity of science be respected. For authors, we will make the submission process easy, the editorial decision deliberate and the publication timely. For readers, we will communicate various, even conflicting, ideas, in which truth will ultimately be defended by debate. 